2 Bernersen B, Johnsen R, Bostad L, Straume B, Sommer AI, Burhol PG. Is Helicobacter pylori the cause of dyspepsia? BMJ 1992;304:1276-9.

3 Armstrong D. Helicobacter pylori infection and dyspepsia. Scand J Gastroenterol 1996;31(suppl 215):38-47.

4 Bytzer P. Diagnosing dyspepsia-any controversies left? Gastroenterology 1996;110:302-6.

5 Strauss RM, Wang TC, Kelsey PB, Campton CC, Ferraro MT, Perez-Perez $\mathrm{G}$, et al. Association of Helicobacter pylori infection with dyspeptic symptoms in patients undergoing gastroduodenoscopy. Am J Med 1990;89:464-9.

6 Schubert TT, Schubert AB, Ma CK. Symptoms, gastritis, and Helicobacter pylori in patients referred for endoscopy. Gastrointest Endosc 1992;38:357-60.

7 Nandurkar S, Talley NJ, Xia H, Mitchell H, Hazell S, Jones M. Dyspepsia in the community is linked to smoking and aspirin use but not to Helicobacter pylori infection. Arch Intern Med 1998;158:1427-33.

8 Talley NJ. A critique of therapeutic trials in Helicobacter pylori-positive functional dyspepsia. Gastroenterology 1994;106:1174-83.

9 Veldhuyzen van Zanten SJO, Cleary C, Talley NJ, Peterson TC, Nyren O, Bradley L, et al. Drug treatment of functional dyspepsia: a systematic analysis of trial methodology with recommendations for design of future trials Am J Gastroenterol 1996:91:660-73.

10 Laheij RJF, Jansen JBMJ, Vandelisdonk EH, Verbeek ALM. Symptom improvement through eradication of Helicobacter pylori with non-ulcer dyspepsia. Alimen Pharmacol Ther 1996;10:843-50

11 Talley NJ, Hunt RH. What role does Helicobacter pylori play in non ulcer dyspepsia? Arguments for and against $\mathrm{H}$. pylori being associated with dyspeptic symptoms. Gastroenterology 1997;(suppl 6):67-77S.

12 McCarthy C, Patchett S, Collins RM, Beattie S, Keane C, O'Morain C. Long term prospective study of Helicobacter pylori in non-ulcer dyspepsia Dig Dis Sci 1995;40:114-9.

13 Gilvarry J, Buckley MJM, Beattie S, Hamilton H, O'Morain CA Eradication of Helicobacter pylori affects symptoms in non-ulce dyspepsia. Scand J Gastroenterol 1997;32:535-40.

14 Junghard O, Talley NJ, Wiklund I. Validation of seven graded diary cards for severity of dyspeptic symptoms in patients with non-ulcer dyspepsia. Europ J Surg 1998:583:106-11.

15 Dixon MF, Genta RM, Yardley JH, Correa P. Classification and grading of gastritis. The updated Sydney system. International workshop in the histology of gastritis, Houston 1994. Am J Surg Pathol 1996;20:1161-81.
16 Dominguez-Munoz JE, Leodolter A, Sauerbruch T, Malfartheiner P. A citric acid solution is an optimal test drink in the ${ }^{13} \mathrm{C}$-urea breath test for the diagnosis of Helicobacter pylori infection. Gut 1997;40:459-62.

17 Revicki DA, Wood M, Wiklund I, Crawley J. Reliability and validity of the gastrointestinal symptom rating scale in patients with gastroesophageal reflux. Oual Life Res 1998;7:75-83.

18 Goves J, Oldring JK, Kerr D, Dallara RG, Roffe EJ, Powell JA, et al. First line treatment with omeprazole provides an effective and superior alternative strategy in the management of dyspepsia compared to antacid/alginate liquid: a multicentre study in general practice. Aliment Pharmacol Ther 1998;12:147-57.

19 Wiklund I, Bardhan KD, Muller-Lisner S, Bigard MA, Bianchi-Porro G, Ponce J, et al. Quality of life during acute and intermittent treatment of gastroesophageal reflux disease with omeprazole compared with ranitidine. Results from a multicentre study. Ital J Gastroenterol Hepatol 1998;30:19-27.

20 Dimenas E, Glise H, Hallerback B, Hernqvist H, Svedlund J, Wiklund I Well-being and gastrointestinal symptoms among patients referred to endoscopy owing to suspected duodenal ulcer. Scand J Gastroenterol 1995;30:1046-52

21 Talley NJ, Weaver AL, Zinsmeister AR, Melton LJ III. Onset and disappearance of gastrointestinal symptoms and functional gastrointestinal disorders. Am J Epidemiol 1992;136:165-77.

22 McColl K, Murray L, El-Omar E, Dickson A, El-Nujumi A, Wirz A, et al. Symptomatic benefit from eradicating Helicobacter pylori infection in patients with nonulcer dyspepsia. N Engl J Med 1998;26:1869-74.

23 Blum A, Talley NJ, O'Morain C, Veldhuyzen Van Zanten S, Labenz J, Stolte M, et al. Lack of effect of treating Helicobacter pylori infection in patients with nonulcer dyspepsia. N Engl J Med 1998:26:1875-81.

24 Trespi E, Broglia F, Villani L, Luinetti O, Fiocca R, Solcia E. Distinct profiles of gastritis in dyspepsia subgroups. Their different clinical responses to gastritis healing after Helicobacter pylori eradication. Scand J Gastroenterol 1994;29:884-8.

25 Talley NJ, Silverstein MD, Agreus L, Nyren O, Sonnenberg A, Holtmann G. AGA technical review: evaluation of dyspepsia. Gastroenterolog 1997;114:582-95

26 Axon A, Forman D. Helicobacter gastroduodenitis: a serious infectious disease. $B M J$ 1997;314:1430-1.

(Accepted 21 January 1999)

\title{
Systematic review of day hospital care for elderly people
}

\author{
Anne Forster, John Young, Peter Langhorne on behalf of the Day Hospital Group
}

\author{
Abstract \\ Objective To examine the effectiveness of day \\ hospital attendance in prolonging independent living \\ for elderly people. \\ Design Systematic review of 12 controlled clinical \\ trials (available by January 1997) comparing day \\ hospital care with comprehensive care (five trials), \\ domiciliary care (four trials), or no comprehensive \\ care (three trials). \\ Subjects 2867 elderly people. \\ Main outcome measures Death, institutionalisation, \\ disability, global "poor outcome," and use of resources. \\ Results Overall, there was no significant difference \\ between day hospitals and alternative services for \\ death, disability, or use of resources. However, \\ compared with subjects receiving no comprehensive \\ care, patients attending day hospitals had a lower \\ odds of death or "poor" outcome $(0.72,95 \%$ \\ confidence interval 0.53 to $0.99 ; \mathrm{P}<0.05)$ and \\ functional deterioration $(0.61,0.38$ to $0.97 ; \mathrm{P}<0.05)$. \\ The day hospital group showed trends towards \\ reductions in hospital bed use and placement in \\ institutional care. Eight trials reported treatment costs, \\ six of which reported that day hospital attendance was \\ more expensive than other care, although only two \\ analyses took into account cost of long term care. \\ Conclusions Day hospital care seems to be an \\ effective service for elderly people who need
}

rehabilitation but may have no clear advantage over other comprehensive care. Methodological problems limit these conclusions, and further randomised trials are justifiable.

\section{Introduction}

Geriatric day hospitals developed rapidly in the United Kingdom in the 1960s as an important component of care provision. The model has since been widely applied in several Western countries. Day hospitals provide multidisciplinary assessment and rehabilitation in an outpatient setting and have a pivotal position between hospital and home based services. Although there is considerable descriptive literature on day hospital care, ${ }^{1}$ concern has been expressed that evidence for effectiveness is equivocal and that day hospital care is expensive. ${ }^{2}$ We therefore undertook a systematic review of the randomised trials of day hospital care.

\section{Methods}

The primary question addressed was whether older patients attending a day hospital would experience better outcomes than those receiving alternative forms of care. We anticipated considerable heterogeneity in both the intervention and control services and so specified key subgroup comparisons before reviewing the trials.
Department of Health Care for the Elderly, St Luke's Hospital, Bradford BD5 0NA

Anne Forster, research physiotherapist John Young, consultant physician

Academic Section of Geriatric Medicine, Royal Infirmary, Glasgow G4 OSF Peter Langhorne, senior lecturer

Correspondence to: Dr Forster a.forster@ leeds.ac.uk

BMJ 1999;318:837-41

website

extra

A table with details of the trials included is available on the BMJ's website

www.bmj.com 


\section{Inclusion criteria}

We set out to identify all relevant controlled clinical trials of geriatric day hospital care. A day hospital was defined as an outpatient facility where older patients attend for a full or near full day and receive multidisciplinary rehabilitation in a health care setting. ${ }^{3}$ Trials evaluating social day centres, other types of day hospitals such as those for patients with dementia or psychiatric conditions, and single condition day hospitals were excluded.

\section{Search strategy}

We searched for relevant published and unpublished papers up to January 1997. Our search strategy included Medline, SIGLE (System for Information on Grey Literature in Europe), BIDS (Bath Information and Data Services), CINAHL (Cumulative Index to Nursing and Allied Health), and the Cochrane Library. Key search terms included day hospital, day care, ambulatory care, and outpatient clinic. We also searched Index Medicus, British and international dissertation abstracts, conference abstracts (Society for Research in Rehabilitation, British Geriatrics Society), bibliographies of known trials, and other relevant articles and books. We publicised our work through presentations at geriatric symposia and by contacting authors of previous articles on day hospital care.

\section{Study appraisal and extraction of data}

We selected outcomes to reflect a previous definition of the purpose of day hospital care: "to facilitate and prolong independent living for the elderly in the community." ${ }^{\prime 4}$ Thus death, the need for institutional care, disability, hospital use, and resource use were selected as quantitative outcomes. In anticipation of incomplete data we also defined a global "poor outcome" comprising death or one of the following (in order of preference): resident in institutional care, severe disabil-

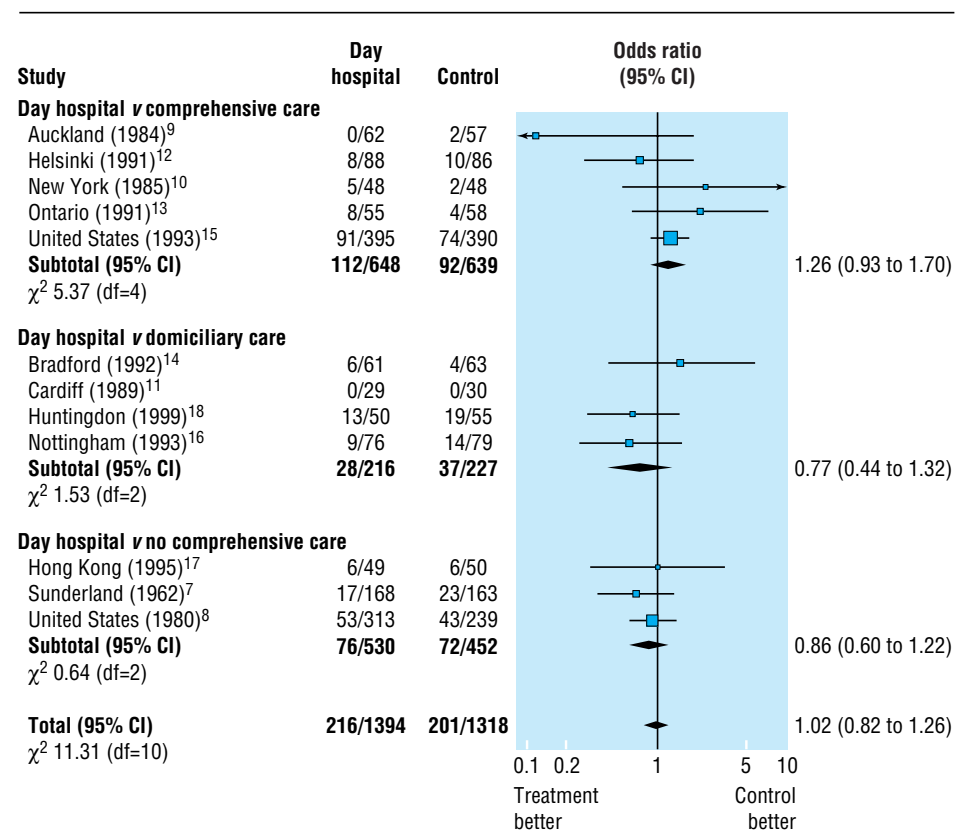

Fig 1 Deaths among patients receiving day hospital care or alternative services. Odds ratios of death by end of follow up were calculated by fixed effects model. Heterogeneity between trials is presented as $\chi^{2}$ ity at end of follow up, or deterioration in physical function during follow up. The research reports were independently assessed by three reviewers to establish eligibility, agree subcategories for the trials based on the treatment comparison, and to extract data.

\section{Statistical methods}

When possible, studies were analysed on an intention to treat basis. Surviving authors were contacted and asked to supply additional information when necessary. Patients who were lost to follow up or for whom outcome data were not available were excluded from the initial analysis. However, they were included in "best case" (all missing data in favour of day hospital care), "neutral" (all missing data recorded at the average event rate for the trial), and "worst case" (all missing data in favour of alternative care) sensitivity analyses.

We calculated odds ratios (with 95\% confidence intervals) for the dichotomous outcomes using standard methods. A fixed effects approach ${ }^{5}$ was used initially and, if substantial heterogeneity was present, we confirmed this with a random effects approach. ${ }^{6}$ Outcomes were recorded at the end of scheduled follow up.

\section{Results}

We identified 703 abstracts, of which 687 were not relevant to the review or of descriptive studies. Sixteen evaluated a service fulfilling our definition of geriatric day hospital care. This analysis includes 12 trials which recruited 2867 subjects. $^{7-18}$ Of the remaining four trials, one has just completed (J Baskett, personal communication); two did not include a random or quasirandom allocation procedure, ${ }^{19}{ }^{20}$ and one was excluded because day hospital attendance was only one component of a complex multiple service intervention. ${ }^{21}$ Details of randomisation procedures, treatment schedules, and numbers of patients followed up are given on the $B M J$ website.

Multidisciplinary outpatient rehabilitation was available at all the day hospital sites. Comparison groups comprised comprehensive elderly care (a range of inpatient, outpatient, and domiciliary geriatric medical services) ${ }^{9} 101213$ 15; domiciliary care (therapy provided in the patient's home ${ }^{11} 1{ }^{16}$ or day centre $\left.{ }^{18}\right)$; and no comprehensive elderly care (patients who were eligible for, but not referred to, existing services). ${ }^{717}$ For the trial by Gladman et $\mathrm{al}^{16}{ }^{16}$ only patients in the health care of the elderly strata have been included as the random treatment allocation of these patients included day hospital care.

\section{Patient characteristics}

One study was run by the Department of Veterans Affairs in the United States and was exceptional in that the sample was $96 \%$ male. ${ }^{15}$ In all trials the mean age of participants was at least 65 years and usually over 70 years. Three trials ${ }^{141617}$ recruited only stroke patients, but the rest had a mixed population. Most patients had significant disability on a variety of scales.

\section{Outcome data}

Details on deaths were published, or provided on request, for all trials. Information about institutionalisation was published in only four studies 79 $^{13} 16$; additional data were provided by the authors for a further six studies. ${ }^{11} 12151718$ Data were also available 
concerning some aspect of disability (11 trials) and use of hospital beds (12 trials).

No significant differences in numbers of deaths occurred between patients attending day hospitals and those receiving any of the alternative services (fig 1). The pooled odds ratio for death was $1.02 \quad(95 \%$ confidence interval 0.82 to1.26). There was no significant heterogeneity between the results of individual trials or categories of trials.

Figure 2 shows that overall there was no significant difference between day hospital and alternative forms of care in preventing death or a "poor" outcome at final follow up (odds ratio 0.90, 0.71 to 1.14; random effects model). However, patients attending day hospitals were less likely to have poor outcome than those receiving no comprehensive care $(0.72,0.53$ to 0.99 ; $\mathrm{P}<0.05)$.

\section{Sensitivity analyses}

Sensitivity analyses indicated that excluding trials with uncertain or insecure randomisation procedures would not substantially affect our conclusions. ${ }^{810} 12$ Data were missing on death for $155(6 \%)$ patients and on death or poor outcome for $174(7 \%)$. Best case and worst case sensitivity analyses include significant benefit $(\mathrm{P}<0.001)$ or harm $(\mathrm{P}<0.05)$ from day hospital care. The most plausible (neutral) sensitivity analysis suggested no effect on death (odds ratio 1.02, $\mathrm{P}>0.05)$ or death and poor outcome $(0.92, \mathrm{P}>0.2)$.

\section{Disability}

Eleven of the trials included a standardised measurement of activities of daily living, ${ }^{8-18}$ but seven different measures were used which could not be combined in a statistical summary. Seven trials ${ }^{811} 121416-18$ provided data on 905 survivors (data missing for $65,7 \%$ ) whose disability scores were monitored during follow up (fig 3). Overall, day hospital patients had a similar chance as controls of suffering deteriorating function (1.11, 0.68 to 1.80 ; random effects model) but tended to have better outcomes than those receiving no comprehensive care $(0.61,0.38$ to $0.97 ; \mathrm{P}<0.05)$

\section{Use of resources}

Institutional care-Eleven trials provided information about the number of patients requiring institutional care at the end of follow up. Overall, there was a trend towards fewer day hospital patients requiring long term (median follow up 12 months) institutional care than those receiving alternative services (table) and the difference was significant in comparison with no comprehensive care.

Use of hospital beds-Average hospital bed use per patient recruited could be calculated for all the trials,

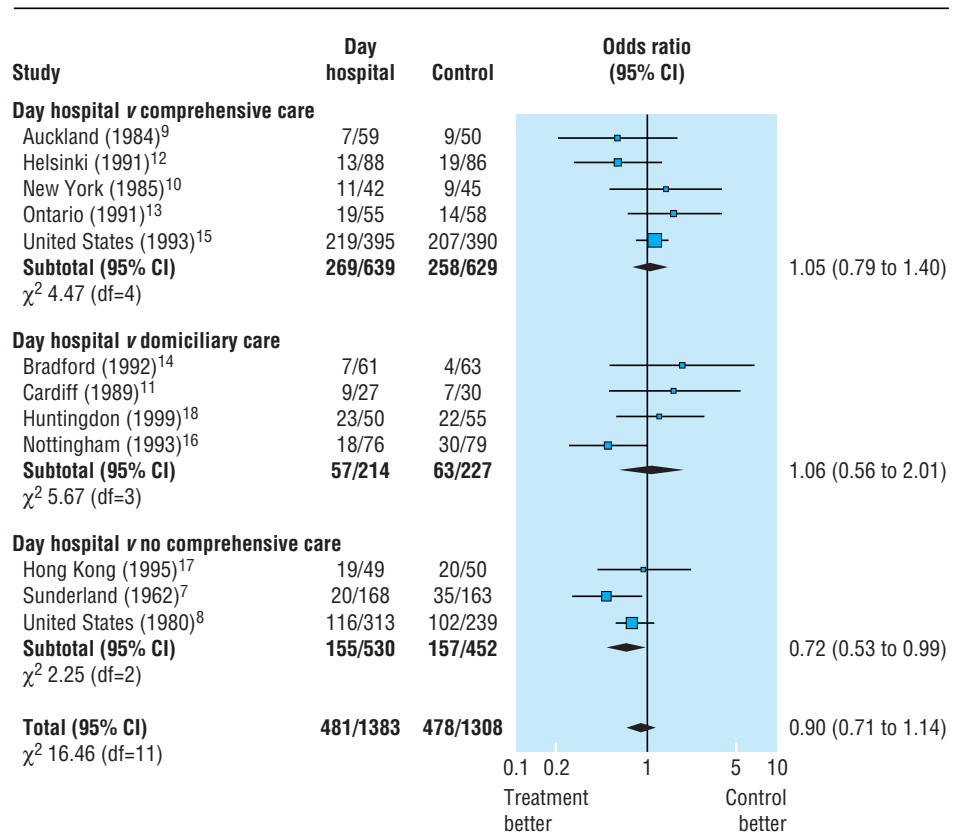

Fig 2 Odds of death or poor outcome in patients receiving day hospital care or alternative services (random effects model). Heterogeneity between trials is presented as $\chi^{2}$

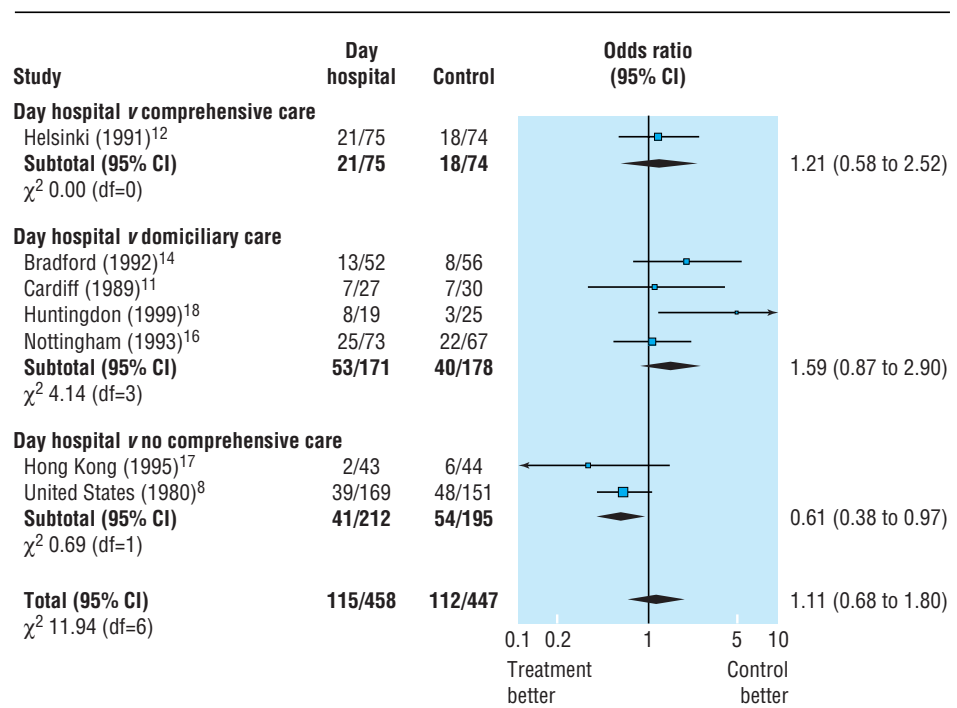

Fig 3 Deterioration in activities of daily living among survivors allocated to day hospital care or alternative services (random effects model). Heterogeneity between trials is presented as $\chi^{2}$

but a measure of variance could not be obtained and therefore we cannot report confidence intervals. The table shows a small reduction in bed use by day hospital patients across all trials (15.0 $v 16.4$ days).

Numbers of patients receiving institutional care at the end of scheduled follow up and use of hospital beds among those allocated to day hospital or alternative services

\begin{tabular}{|c|c|c|c|c|c|}
\hline \multirow[b]{2}{*}{ Control group } & \multicolumn{3}{|c|}{ Institutional care } & \multicolumn{2}{|c|}{ Bed use (days) } \\
\hline & Day hospital & Control & Odds ratio $(95 \% \mathrm{CI})$ & Day hospital & Control \\
\hline Comprehensive care (5 trials) & $151 / 597^{\star}$ & $159 / 584$ & 0.91 (0.70 to 1.19$)$ & 20.5 & 21.4 \\
\hline Domiciliary care (4 trials) & $20 / 216$ & $19 / 227$ & $1.61(0.30$ to 8.55$)$ & 7.7 & 11.1 \\
\hline No comprehensive care (3 trials) & $37 / 411$ & $66 / 403$ & $0.50 \dagger(0.26$ to 0.96$)$ & 11.2 & 11.7 \\
\hline Total & $208 / 1224$ & 244/1214 & 0.77 (0.52 to 1.13$)$ & 15.0 & 16.4 \\
\hline
\end{tabular}

*Data not available for 1 trial.

$\dagger \mathrm{P}<0.05$ (random effects model). 
Costs-Eight trials compared treatment costs, only two of which included costs of nursing home care. ${ }^{10}{ }^{15}$ Six reported that day hospital care was more expensive than the comparison treatment, ${ }^{8915182223}$ and two trials reported that the costs were similar. ${ }^{10}{ }^{17}$

\section{Discussion}

Geriatric day hospitals have several functions, but rehabilitation has been regarded as most important ${ }^{1}$ and was the focus for this systematic review. We selected outcomes to reflect a definition of the core purpose of a geriatric day hospital. ${ }^{4}$ We used a predetermined definition of day hospital care $^{3}$ and identified and categorised comparison services before collecting and analysing data. We excluded day hospitals for patients with specific conditions such as mental illness, dementia, or rheumatoid arthritis.

\section{Limitations of the review}

The main limitations of our review lie in the 30 years over which the trials were done, during which health and social care policies will inevitably have changed, and in the multinational location of the studies. Nevertheless, our data provide the best evidence available on which to judge the effectiveness of day hospitals.

A further problem is the limitations of the trials themselves, in particular the lack of statistical power resulting from small, heterogeneous trials. This raises the possibility of false positive and false negative results. Furthermore, the amount of missing outcome data adds uncertainty to most of our conclusions.

Publication bias remains a possibility, but our search strategy was extensive and included contacting authors of papers on day hospital care around the world. Many of the authors were able to provide unpublished additional information. A funnel plot analysis ${ }^{24}$ did not show any major evidence of missing data.

\section{Findings}

A big problem was that most trials compared day hospital care with an alternative "active" control. Only three trials ${ }^{7817}$ used a comparison group of patients who received neither comprehensive care nor domiciliary rehabilitation. Compared with patients receiving no comprehensive care, patients attending day hospitals had less functional deterioration and institutional care and a small reduction in average hospital bed use. However, there was considerable loss to follow up in these three trials.

When day hospital services were compared with comprehensive elderly care (integrated inpatient, outpatient, and domiciliary services), the outcomes were largely similar. One interpretation is that day hospitals are comparable with an alternative service for which there is considerable evidence of effectiveness. ${ }^{25}$ However, the question arises whether day hospitals provide additional benefits when other comprehensive elderly care services are already in place. Our systematic review does not directly address this question.

We focused on a few specified outcomes, but many other important outcome domains, including patient preference and instrumental daily living activities, could not be examined as these outcomes were not widely available. It was also difficult to determine a summary statistic for disability because different
- The benefits of geriatric day hospital care have been controversial for many years

- This systematic review of 12 randomised trials comparing a variety of day hospitals with a range of alternative services found no overall advantage for day hospital care

- Day hospitals had a possible advantage over no comprehensive care in terms of death or poor outcome, disability, and use of resources

- The costs of day hospital care may be partly offset by a reduced use of hospital beds and institutional care among survivors

measurement instruments were used and analysed in different ways. Moreover, commonly used measures of disability may be insensitive to change in the outpatient setting of a day hospital. ${ }^{26}$ This may explain why six trials reported no significant difference in disability outcome between day hospital and comparison services. Future trials should incorporate measures of intrumental activities of daily living as a more relevant and sensitive outcome.

Our analysis suggests that attending day hospital may reduce patients' use of hospital and institutional care resources. However, costing studies need to balance any possible savings with the direct costs of day hospital care. Several studies have drawn attention to the expense of day hospital services. ${ }^{22}{ }^{23}$ For six of the eight trials reporting cost information, day hospital care was more expensive than the alternative treatment.

On the whole, the trials we included took a pragmatic design approach and attempted to address a broad question of overall efficacy of day hospitals. Given the diversity of patients attending day hospitals and the corresponding diversity of interventions used, future trials need to be large multicentre trials or should examine more focused questions.

An expanded version of this review has been submitted for publication in the Cochrane Library.

Contributors: AF planned and initiated the review, conducted literature searches, assessed the trials, drafted and redrafted the final report. JY planned and initiated the review, assessed trials, and redrafted the final report. PL planned the review, assessed trials, provided methodological support, and redrafted the final report. The day hospital group is formed from the authors of this systematic review and the authors of the original trials who provided additional information about trial procedures and data: S Burch, J Longbottom, M Mckay, C Borland, T Prevost (Huntingdon); Kaisu Pitkala (Helsinki); John Gladman (Nottingham); Susan Hedrick, M L Rothman, M K Chapko, J L Ehreth, P Diehr, T S Inui, R T Connis, P L Grover, J R Kelly (United States); E Hui, C Lum, R L C Kay, J Woo, K H Or (Hong Kong); N Vetter (Cardiff). Victor Cummings, Joan Eagle, and S J Ogle also supported the review.J Baskett provided additional information and T K Kong identified a relevant trial.

Funding: NHS Executive Northern and Yorkshire Region, Stroke Association.

Competing interests: None declared.

1 Research Unit of the Royal College of Physicians and British Geriatric Society. Geriatric day hospitals: their role and guidelines for good practice. London: RCP, 1994.

2 National Audit Office. National health service day hospitals for elderly people in England. London: HMSO, 1994.

3 Siu AL, Morishita L, Blaustein J. Comprehensive geriatric assessment in a day hospital. J Am Ger Soc 1994;42:1094-9. 
4 Donaldson C, Wright KG, Maynard AK, Hamill JD, Sutcliffe E. Day hospitals for the elderly: utilisation and performance. Community Med 1987;9:55-61.

5 Peto R. Why do we need systematic overviews of randomized trials? Stat Med 1987;6:233-40.

6 DerSimonian R, Laird N. Meta-analysis in clinical trials. Controlled Clin Trials 1986;7:177-88

7 Woodford-Williams E, McKeon JA, Trotter IS, Watson D, Bushby C. The day hospital in the community care of the elderly. Gerontology Clinic 1962;4:241-56.

8 Weissert W, Wan T, Livieratos B, Katz S. Effects and costs of day-care services for the chronically ill: a randomized experiment. Medical Care $1980 ; 18: 567-84$.

9 Tucker MA, Davison JG, Ogle SJ. Day hospital rehabilitationeffectiveness and cost in the elderly: a randomised controlled trial. $B M J$ $1984 ; 289: 1209-12$

10 Cummings V, Kerner JF, Arones S, Steinbock C. Day hospital service in rehabilitation medicine: an evaluation. Arch Phys Med Rehabil 1985;66: 86-91.

11 Vetter NJ, Smith A, Sastry D, Tinker G. Day hospital pilot study report. Cardiff : Department of Geriatrics, St David's Hospital, 1989.

12 Pitkala K, Winell K, Tilvis RS. Effects of geriatric day hospital care for home care patients. Arch Gerontol Geriatric 1991;suppl 2:51-4.

13 Eagle DJ, Guyatt GH, Patterson C, Turpie I, Sackett B, Singer J. Effectiveness of a geriatric day hospital. Can Med Assoc J 1991;144:699-704.

14 Young JB, Forster A. The Bradford community stroke trial: results at six months. BMJ 1992;304:1085-9.

15 Hedrick SC, Branch LG, eds. Adult day health care evaluation study. Medical Care 1993;31(suppl):SS1-124.

16 Gladman JRF, Lincoln NB, Barer DH. A randomised controlled trial of domiciliary and hospital-based rehabilitation for stroke patients after discharge from hospital. J Neurol Neurosurg Psychiatry 1993;56:960-6.

17 Hui E, Lum CM, Woo J, Or KH, Kay RLC. Outcomes of elderly stroke patients day hospital versus conventional medical management. Stroke 1995;26:1616-9.

18 Burch S, Longbottom J, McKay M, Borland C, Prevost T. A randomised controlled trial of day hospital and day centre therapy. Clin Rehab (in press).

19 Weiler PG, Kim P, Pickard LS. Health care for elderly Americans: evaluation of an adult day health care model. Medical Care 1976;14:700-8.

20 Sherwood S, Morris JN, Ruchlin HS. Alternative paths to long-term care: nursing home, geriatric day hospital, senior center, and domiciliary care options. Am J Public Health 1986:76:38-44.

21 Skellie FA, Mobley GM, Coan RE. Cost-effectiveness of community-based long-term care: current findings of Georgia's alternative health services project. Am J Public Health 1982;72:353-8.

22 Young J, Forster A. Day hospital and home physiotherapy for stroke patients: a comparative cost-effectiveness study. $J R$ Coll Phys Lond $1993 ; 27: 252-7$

23 Gladman J, Whynes D, Lincoln N. Cost comparison of domiciliary and hospital-based stroke rehabilitation. Age Ageing 1994;23:241-5.

24 Egger M, Smith GD, Schneider M, Minder C. Bias in meta-analysis Egger M, Smith GD, Schneider M, Minder C. Bias in
detected by a simple, graphical test. BMJ 1997:315:629-34.

25 Stuck AE, Siu AL, Wieland GD, Adams J, Rubenstein LZ. Comprehensive geriatric assessment: a meta-analysis of controlled trials Lance 1993;342:1032-6.

26 Parker SG, Du X, Bardsley MJ, Goodfellow J, Cooper RG, Cleary R, et al. Measuring outcomes in care of the elderly. $J R$ Coll Phys Lond 1994;28:428-33.

(Accepted 29 January 1999)

\section{Paralytic poliomyelitis associated with live oral poliomyelitis vaccine in child with HIV infection in Zimbabwe: case report}

Inam Chitsike, Ralph van Furth

\begin{abstract}
Objective To describe a complication of oral vaccination with live, attenuated poliomyelitis virus in a child infected with HIV.

Design Case report.

Setting Teaching hospital in Harare, Zimbabwe.

Subjects A boy of 41/2 years and his mother.

Main outcome measures Results of clinical and

laboratory investigations.

Results Two weeks after receiving the second dose of oral poliomyelitis vaccine during national

immunisation days the child developed paralysis of the right leg. He had a high titre of antibodies against poliovirus type 2, as well as antibodies against HIV-1, a low CD4 count, a ratio of CD4 to CD8 count of 0.47 , and hypergammaglobulinaemia. He did not have any antibodies against diphtheria, tetanus, or poliovirus types 1 and 3, although he had been given diphtheria, tetanus, and pertussis and oral polio vaccines during his first year and a booster of the diphtheria, tetanus, and pertussis vaccine at 24 months. He had no clinical symptoms of AIDS, but his mother had AIDS and tuberculosis.

Conclusion Paralytic poliomyelitis in this child with HIV infection was caused by poliovirus type 2 after oral poliomyelitis vaccine.
\end{abstract}

\section{Introduction}

The expanded immunisation programme in Zimbabwe started in 1981 and has a coverage of around 85\% in most areas of the country. ${ }^{1}$ The vaccination schedule is three doses of trivalent oral, live attenuated, poliomyelitis vaccine and diphtheria, tetanus, and pertussis vaccine at 3,4 , and 5 months of age, with a booster of diphtheria, tetanus, and pertussis vaccine at 18 months. In line with the World Health Organisation's goal of eradicating poliomyelitis by $2000,{ }^{2}$ children under 5 years old in Zimbabwe received two doses of oral vaccine, regardless of their vaccination history, during the national immunisation days in $1996 .{ }^{3}$ Most children infected with HIV live in developing countries, so the influence of HIV infection on vaccination against poliomyelitis is relevant. We describe a case of paralytic poliomyelitis in a child with HIV infection after vaccination with oral poliomyelitis vaccine.

\section{Case history}

A boy aged $4 \frac{1}{2} 2$ years who was infected with HIV had been vaccinated with diphtheria, tetanus, and pertussis vaccine and oral poliomyelitis vaccine at the ages of 3 , 4 , and 5 months and had received a booster of diphtheria, tetanus, and pertussis vaccine at 24 months. On the national immunisation days of 1996 (7 August and 29 September) he received oral poliomyelitis vaccine, and a few days after the second immunisation he developed diarrhoea and fever. Two weeks later he developed weakness in his right leg. He was seen at a local primary healthcare clinic, but laboratory tests were not performed.

Three months later, in January 1997, he came to Parirenyatwa Teaching Hospital in Harare because of
Departments of
Paediatrics and
Immunology,
Medical School of
the University of
Zimbabwe, PO Box
A 178, Harare,

BMJ VOLUME 318 27 MARCH 1999 www.bmj.com 